\title{
Hyponatremia caused by excessive intake of water as a form of child abuse
}

\author{
Min A Joo, MD, \\ Eun Young Kim, MD, PhD \\ Department of Pediatrics, Chosun \\ University School of Medicine, \\ Gwangju, Korea
}

\begin{abstract}
Hyponatremia is the most common electrolyte disorder that requires careful management. Water intoxication with hyponatremia is rare condition that originated from overhydration. Water intoxication, also known as dilutional hyponatremia, develops only because the intake of water exceeds the kidney's ability to eliminate water. Causes of this water intoxication include psychiatric disorder, forced water intake as a form of child abuse and iatrogenic infusion of excessive hypotonic fluid. We experienced and reported a case of symptomatic hyponatremia by forced water intake as a form of child abuse.
\end{abstract}

Keywords: Hyponatremia, Water intoxication, Child abuse

\section{Introduction}

Hyponatremia is an electrolyte imbalance indicated by a lower than $135 \mathrm{mEq} / \mathrm{L}$ of sodium level in the blood. Water intoxication is a rare phenomenon that occurs due to an excessive intake of water, and when the amount of water intake exceeds that of water excretion in the kidney. As a result, the sodium concentration in the blood is diluted, and hyponatremia develops. Water intoxication is usually observed in psychiatric patients, child-abuse victims, and iatrogenic cases. Reported herein is a case of hyponatremia that was caused by an excessive intake of water as a form of child abuse.

\section{Case report}

A 9-year-and 3-month-old girl was admitted with the chief complaint of drowsy mentation that developed four hours prior to her admission. Her stepfather forced her to drink two $1.8 \mathrm{~L}$ bottles of water within $1-2$ hours $\left(1,800-3,600 \mathrm{~mL} / \mathrm{hr}, 3.1 \mathrm{~L} / \mathrm{m}^{2}\right)$, and she vomited and complained of headaches before she fell asleep, and since then, she had been in a hypnoleptic state. She was taken to a general practitioner (GP) clinic where she underwent a blood test that showed a finding of $\mathrm{Na} 118 \mathrm{mEq} / \mathrm{L}$ of hyponatremia. She was then transferred to the hospital.

Her family history showed that her biological father passed away when she was 3-year-old, and she was living with her stepfather, mother, and an 11-month-old stepsister.

She underwent an appendicitis surgery 8 months before this incident, and her physician advised her to drink much water after the surgery because she was constipated. Since she had been discharged after the surgery, her stepfather had her drink two bottles of $1.8 \mathrm{~L}$ - water a day. On the day she was admitted, she lied to her stepfather that she had drunk all the water, but she was caught in a lie, so her stepfather had her drink two bottles of $1.8 \mathrm{~L}$ - water at once. In the past whenever she drank two bottles of water at once, she experienced a depressed mental status, but no specific assessment was performed. Her stepfather was reported to have hit her on the back, arm, and thigh several times a day because she often lied.

The patient's weight and height were within a normal range, and vital signs were stable. There were no changes in her body weight. When she was admitted, her consciousness was drowsy,

Address for correspondence:

Eun Young Kim, MD, PhD

Department of Pediatrics,

Chosun University School of

Medicine, 309 Pilmun-daero,

Dong-gu, Gwangju 501-759, Korea

Tel: +82-62-220-3055

Fax: +82-62-227-2904

E-mail: sskey@chosun.ac.kr 
and various sizes of bruises were found on the back, arms, and thigh (Fig. 1).

Other than those, no other abnormality was observed during physical and neurologic examinations.

Results of the blood tests that were conducted at her admission showed: hemoglobin, $12.1 \mathrm{~g} / \mathrm{dL}$; hematocrit, 35.8\%; white blood cell, 25,010/ $\mu \mathrm{L}$; platelet, 329,000/ $\mu \mathrm{L} ; \mathrm{Na}, 127 \mathrm{mEq} /$ $\mathrm{L}$; K, $2.9 \mathrm{mEq} / \mathrm{L}$; Cl, $91 \mathrm{mEq} / \mathrm{L}$; serum osmolarity, $260 \mathrm{mmol} /$ $\mathrm{kg}$; urine osmolarity, $119 \mathrm{mmol} / \mathrm{kg}$; urine specific gravity, 1.004; and urine $\mathrm{Na}, 19 \mathrm{mEq} / \mathrm{L}$. The results of the adrenal and thyroid glands tests for the differentiation from other diseases that showed the symptoms of hyponatremia were within a normal range, and the antidiuretic hormone level was also normal.

In the chest X-ray images that were obtained when the patient was admitted, and in the brain computed tomography (CT) images from the previous GP clinic, no abnormality was observed (Fig. 2).

Based on these results, the patient was diagnosed with hyponatremia caused by the excessive intake of water as a form of child abuse. Intravenous fluid therapy was conducted, and at two days after her admission, hyponatremia was corrected, and her consciousness reverted to a normal state. When the patient was discharged, we consulted a one-stop center in Chosun University Hospital to prevent further abuse of the child, and they contacted a child protection agency. The agency reported the stepfather to the police and requested that the child be separated from him. As a result of the outpatient follow-up, the child showed a clear consciousness state with fine systemic findings.

\section{Discussion}

Hyponatremia is one of the most common electrolyte disorders, which has high prevalence and mortality rates ${ }^{1)}$.

The control of body water level and electrolyte balance are closely related with the hypothalamus. When $0.5 \%$ or more of body water is lost, we feel thirsty. The kidney can excrete about

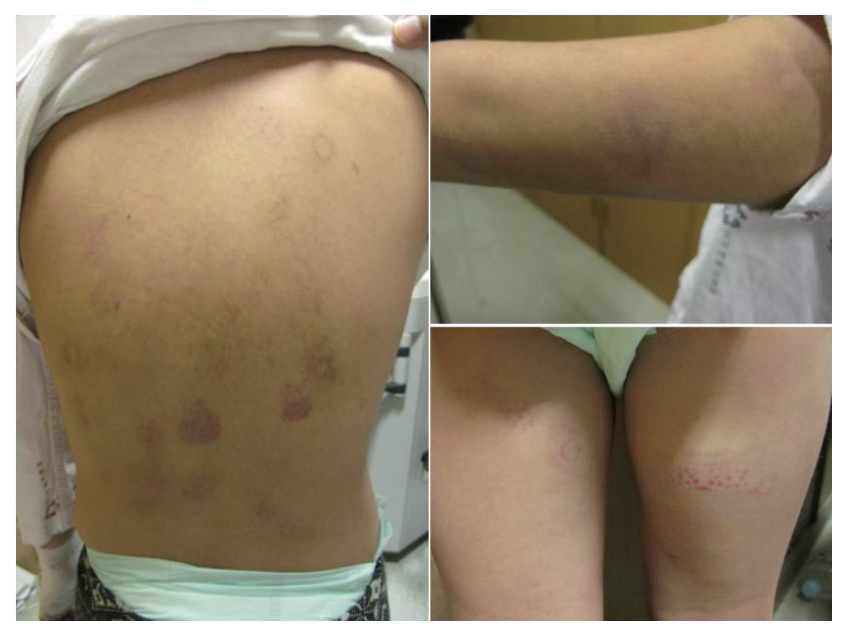

Fig. 1. Various sizes of bruises on patient's back, arm, and thigh.
20-28 L of water a day to control water load, and an excessive intake of water rarely causes hyponatremia ${ }^{2)}$.

A decrease in sodium level inhibits an antidiuretic hormone $(\mathrm{ADH})$ secretion, and consequently, the excreted amount of water via the kidney increases. Hyponatremia develops only when the water-intake amount exceeds the waterexcretion capacity of the kidney. Particularly in infants whose kidney function is not matured, the risk of water intoxication increases ${ }^{3,4)}$. Hyponatremia usually develops in patients with mental diseases such as schizophrenia, in infants during their swimming classes, and in the cases of hypotonic saline administration, water irrigation, and excessive intake of water as a form of child abuse $e^{5-7)}$.

Symptomatic hyponatremia can occur when one drinks 3-4 L of water ${ }^{8}$. Severe hyponatremia occurs when too much water, more than what the kidney can excrete, is inhaled. The water excretion rate of a healthy adult is about $20 \mathrm{~L} /$ day and does not exceed $800-1,000 \mathrm{~mL} / \mathrm{hr}^{9)}$. Thus, the maximum amount of water that a person with normal renal function can drink is 800-1,000 $\mathrm{mL} / \mathrm{hr}$ to avoid hyponatremia symptoms.

In the cases of hyponatremia, the osmolarity of the extracellular space is low, and that in the intracellular space is high, so water is moved from the extracellular space to the intracellular space to maintain the osmolarity at a consistent level. When the amount of intracellular water increases, cellular edema develops. The cellular edema in the brain can be more dangerous than in other tissues because the brain is confined within the skull ${ }^{10)}$.

Symptoms of hyponatremia can occur more easily in children. Since hyponatremic encephalopathy of children can occur with a higher sodium concentration than in adults, children should start treatment at the appropriate time. Otherwise, their prognosis will be bad. This is attributed to the smaller space in

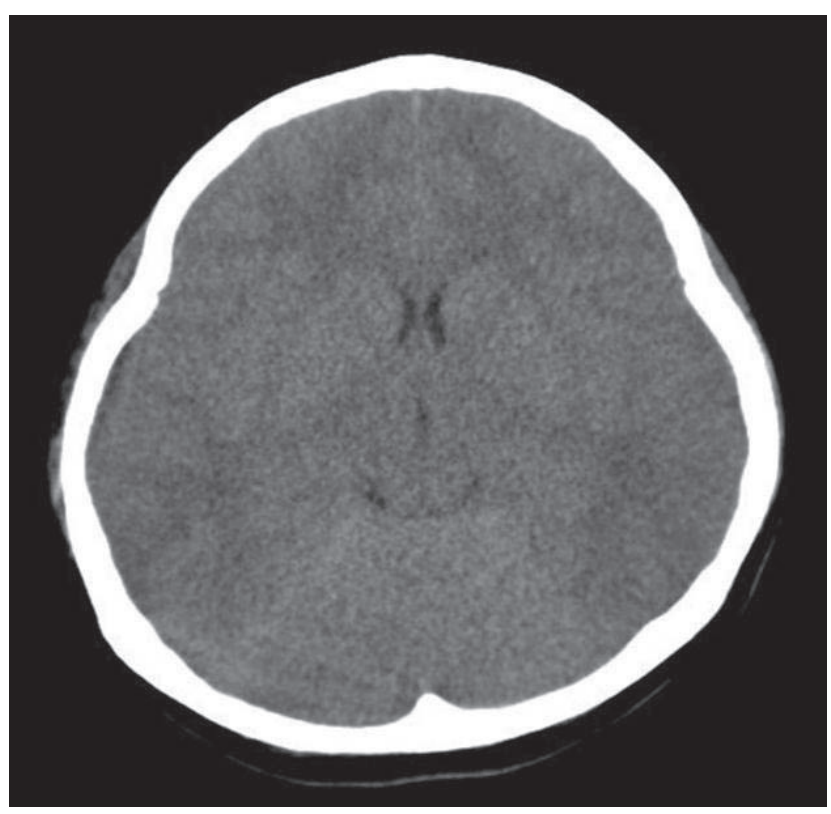

Fig. 2. The patient's brain computed tomography: no visible abnormality 
which the brain can expand in children because of their larger brain-to-skull size ratio ${ }^{11)}$.

The symptoms and signs of water intoxication were described for the first time by Rowntree in 1923 (quoted from ${ }^{2}$ ). The early-stage symptoms may include fatigue, nausea, vomiting, headaches, and blurred vision, as well as mental status changes such as confusion, restlessness, irritability, and lethargy. The signs may include muscle tremors, muscle cramps, psychosis, seizures, increased salivation, diarrhea, hyperpyrexia, and anhidrosis. In extreme cases, pulmonary and brain edema can lead to a coma and death. In particular, when the serum sodium concentration level is extremely low, or the level drops abruptly, a convulsion or coma develops as an initial symptom.

For the diagnosis of hyponatremia, detailed historytaking, physical examinations, laboratory findings, and image findings are necessary. Through detailed history-taking and physical examinations, patients' underlying diseases can be understood, and the status of extracellular fluid can be assessed. The levels of serum osmolarity, urine osmolarity, and urine sodium concentration are important to find out the cause of hyponatremia ${ }^{12)}$. Additionally, the functions of thyroid and glucocorticoid hormones need to be assessed ${ }^{13)}$. Using chest $\mathrm{X}$-ray, patients' fluid status and the pulmonary pathology that can cause the syndrome of an inappropriate secretion of $\mathrm{ADH}$ (SIADH) can be diagnosed. According to clinical symptoms, brain or abdomen CT may be necessary.

Since acute hyponatremia can cause cerebral edema, cerebral herniation, and even death ${ }^{14)}$, a fast treatment is required.

Cerebral edema can occur more severely in patients with acute hyponatremia (i.e., it can develop in 48 hours or less). The main causes of morbidity and mortality are the brainstem herniation and the mechanical pressure on the midbrain structure.

The main causes of morbidity and mortality due to chronic hyponatremia are status epilepticus and cerebral pontine myelinolysis, which occur when the $\mathrm{Na}$ level is less than or equal to $110 \mathrm{mEq} / \mathrm{L}^{15,16)}$.

When the symptoms of hyponatremia appear, hypertonic saline $(3 \% \mathrm{NaCl})$ is administered. During the administration, the electrolyte level should be checked every two hours to decide when to stop administering the saline. When hyponatremia is too quickly corrected, central pontine myelinolysis may develop, so the serum sodium level should not be corrected by $12 \mathrm{mEq} /$ L/24 hr or more.

Child abuse can occur in different forms. Dine and McGovern ${ }^{6}$ reported that the most commonly reported form of abuse in cases of intentional child poisoning is excessive salt ingestion with water restriction, followed by excessive water ingestion. Barbiturates and tranquilizers were also common child abuse agents. Pless et al. ${ }^{17)}$ reported that among the pediatric patients who visited hospital emergency rooms due to accidents, $1.3-15 \%$ were presumed to have been victims of abuse or neglect. Pai et al. ${ }^{18)}$ reported that the proportion of child abuse cases declared by doctors in Korea is lower than that in developed countries. However, no case has been reported of hyponatremia caused by excessive water intake as a form of child abuse in Korea.

In the hyponatremia cases that were caused by water intoxication, the possibility of forced intake of water as a form of child abuse should be taken into consideration as described in this case.

\section{Conflict of interest}

No potential conflict of interest relevant to this article was reported.

\section{Acknowledgments}

This was supported by research funds from Chosun University Hospital 2013.

\section{References}

1. Smith DM, McKenna K, Thompson CJ. Hyponatraemia. Clin Endocrinol (Oxf) 2000;52:667-78.

2. Weiss GJ. Non-psychogenic polydipsia with hyponatremia. Internet J Nephrol [Internet]. 2005 [cited 2012 Nov 24]; 2(1): [about 3 p.]. Available from: http://archive.ispub. $\mathrm{com} /$ journal/the-internet-journal-of-nephrology/ volume-2-number-1/non-psychogenic-polydipsia-withhyponatremia.html\#sthash.Hb4esWoH.dpbs.

3. Schulman J. Infantile water intoxication at home. Pediatrics 1980;66:119-20.

4. Bruce RC, Kliegman RM. Hyponatremic seizures secondary to oral water intoxication in infancy: association with commercial bottled drinking water. Pediatrics 1997;100:E4.

5. Arieff AI, Kronlund BA. Fatal child abuse by forced water intoxication. Pediatrics 1999;103(6 Pt 1):1292-5.

6. Dine MS, McGovern ME. Intentional poisoning of children: an overlooked category of child abuse: report of seven cases and review of the literature. Pediatrics 1982;70:32-5.

7. Dugan S, Holliday MA. Water intoxication in two infants following the voluntary ingestion of excessive fluids. Pediatrics 1967;39:418-20.

8. Jose CJ, Perez-Cruet J. Incidence and morbidity of selfinduced water intoxication in state mental hospital patients. Am J Psychiatry 1979;136:221-2.

9. Verbalis JG, Goldsmith SR, Greenberg A, Schrier RW, Sterns RH. Hyponatremia treatment guidelines 2007: expert panel recommendations. Am J Med 2007;120(11 Suppl 1):S1-21.

10. Radojevic N, Bjelogrlic B, Aleksic V, Rancic N, Samardzic M, Petkovic $\mathrm{S}$, et al. Forensic aspects of water intoxication: four case reports and review of relevant literature. Forensic Sci Int 2012;220:1-5.

11. Moritz ML, Ayus JC. Disorders of water metabolism in children: hyponatremia and hypernatremia. Pediatr Rev 2002;23:371-80. 
12. Yeates KE, Singer M, Morton AR. Salt and water: a simple approach to hyponatremia. CMAJ 2004;170:365-9.

13. Verbalis JG. Hyponatraemia. Baillieres Clin Endocrinol Metab 1989;3:499-530.

14. Fraser CL, Arieff AI. Fatal central diabetes mellitus and insipidus resulting from untreated hyponatremia: a new syndrome. Ann Intern Med 1990;112:113-9.

15. Waikar SS, Mount DB, Curhan GC. Mortality after hospitalization with mild, moderate, and severe hyponatremia. Am J Med 2009;122:857-65.
16. Sajadieh A, Binici Z, Mouridsen MR, Nielsen OW, Hansen JF, Haugaard SB. Mild hyponatremia carries a poor prognosis in community subjects. Am J Med 2009;122:67986.

17. Pless IB, Sibald AD, Smith MA, Russell MD. A reappraisal of the frequency of child abuse seen in pediatric emergency rooms. Child Abuse Negl 1987;11:193-200.

18. Pai KS, Kim SY, Chung YK, Ryu KH. The present state of chid abuse in Korea and its system for child protection. Korean J Pediatr 2009;52:1185-93. 